\title{
PENGARUH MODEL PEMBELAJARAN PETA PIKIRAN (MIND MAPPING) TERHADAP HASIL BELAJAR MATA PELAJARAN ILMU BAHAN BANGUNAN PADA SISWA KELAS X PROGRAM KEAHLIAN KONTRUKSI BATU BETON SMK NEGERI 1 LINTONGNIHUTA
}

\author{
Banget S Lumbantoruan' ${ }^{1}$, Juanda Sianipar ${ }^{2}$ \\ ${ }^{1}$ Alumni Program Studi Pendidikan Teknik Bangunan, Fakultas Teknik UNIMED \\ ${ }^{2}$ Dosen Pengajar Jurusan Pendidikan Teknik Bangunan, Fakultas Teknik UNIMED \\ (sianiparjuanda@gmail.com)
}

\begin{abstract}
ABSTRAK
Penelitian ini bertujuan untuk mengetahui besarnya pengaruh model pembelajaran mind mapping dibandingkan dengan pembelajaran konvensional dan besarnya pengaruh penerapan model pembelajaran mind mapping lebih tinggi dibandingkan pembelajaran konvensional pada siswa kelas $\mathrm{X}$ SMK Negeri 1 Lintongnihuta semester genap Tahun Ajaran 2014/2015 yang berjumlah 30 siswa untuk kelas eksperimen dan 30 siswa kelas kontrol. Rancangan penelitian yang digunakan adalah penelitian quasi eksperimen. Prosedur perlakuan dikemas ke dalam RPP. Dimana perlakuan pada kelas eksperimen KBB-1 menggunakan model pembelajaran mind mapping sedangkan pada kels kontrol KBB-2 menggunakan pembelajaran konvensional materi mempelajari jenis-jenis kayu, sifat dan karateristik sebagai bahan bangunan. Penelitian ini peneliti menggunakan tes objektif sebanyak 30 soal, yang mana sebelumnya tes ini ada 40 soal, akan tetapi setelah diujicobakan pada kelas XI di luar sampel penelitian untuk melihat kesahian tes, terdapat 30 soal yang memenuhi analisis instrument tes dengan reliabilitas soal sebesar 0.9308 . Berdasarkan hasil uji yang telah dilakukan, data pre-tes dan post-tes dari kedua sampel berdistribusi normal dan memiliki varians yang seragam (homogen).

Hasil penelitian menunjukan bahwa 1) penggunaan model mind mapping memberikan pengaruh yang berbeda terhadap hasil belajar ilmu bahan bangunan pada siswa kelas X Progran Keahlian Kontruksi Batu Beton di SMK Negeri 1 Lintongnihuta Tahun Ajaran 2014/2015 dimana berdasarkan hasil pengujian hipotesis anava satu jalan untuk post-tes $F_{\text {hitung }}=50,948>F_{\text {tabel }}=4,008$. 2) penggunaan model pembelajaran mind mapping memberikan pengaruh yang lebih tinggi dibandingkan dengan pembelajaran konvensioanal, yang dilanjutkan ke uji-t diperoleh $t_{\text {hitung }}=7,138>t_{\text {tabel }}=1,689$.
\end{abstract}

Kata Kunci :Mind mapping, Hasil Belajar, Ilmu Bahan Bangunan

\begin{abstract}
This study aims to determine the influence of mind mapping learning model gives a different effect than the conventional learning and the effect of the application of mind mapping learning model gives a higher impact than conventional learning in class X SMK 1 Lintongnihuta semester Academic Year 2014/2015 totaling 30 students to 30 students experimental class and control class. The design of the study is quasi-experimental study. Treatment procedure is packed into the RPP. Where the treatment in the experimental class KBB-1 using mind mapping learning model, while the control kels KBB-2 using conventional learning materials to study the types of wood, properties and characteristics as a building material. For memproleh data needed in the study, researchers used an objective test of 30 questions, which earlier this test there are 40 questions, but once tested in class XI out sample to see kesahian test, there are 30 questions that meet the analytical test instrument with about the reliability of 0.9308. Based on the test results that have been done, it is known that the data pre-test and post-test of the second sample has a normal distribution and uniform variance (homogeneous).
\end{abstract}


The results showed that: 1) the use of mind mapping models give a different effect on the results of studying the building materials in class $X$ program as Stone Concrete Construction Expertise in SMK Negeri 1 Lintongnihuta Academic Year 2014/2015 which is based on the results of hypothesis testing ANOVA one way to post -test Fhitung $=50.948>$ Ftabel $=4.008$. 2) the use of mind mapping learning model gives a higher impact than the learning konvensioanal, which continued into the $t$-test obtained $t=7.138>t$ table $=1.689$.

Keywords: Mind mapping, Learning Outcomes, Science Building Materials

\section{Pendahuluan}

Pendidikan Nasional adalah usaha sadar dan terencana untuk mewujudkan suasana belajar dan proses pembelajaran agar peserta didik secara aktif mengembangkan potensi dirinya untuk memiliki kekuatan spiritual keagamaan, pengendalian diri, kepribadian, kecerdasan, akhlak mulia, serta keterampilan yang diperlukan dirinya, masyarakat, bangsa dan Negara sehingga tercapainya tujuan pendidikan (dalam Undang-Undang No. 20 Tahun 2003).

Bila dikaitkan dengan tujuan pendidikan khususnya Sekolah Menengah Kejuruan (SMK), maka tujuan pengajaran diarahkan untuk menciptakan manusia/tenaga kerja yang siap memasuki lapangan kerja. Hal ini tertuang dalam tujuan SMK Negeri 1 Lintongnihuta, yakni: membekali peserta didik dengan keterampilan, pengetahuan dan sikap agar kompeten dalam: (1) berusaha mewujudkan lembaga pendidikan dan latihan yang berkualitas, (2) mempersiapkan peserta didik agar menjadi sumber daya manusia yang professional, mempunyai kemampuan untuk mandiri dan mampu mengisi yang ada pada dunia usaha/dunia industri/pemerintah sebagai tenaga kerja tingkat menengah sesuai dengan kopetensi dalam program keahlian, (3) membekali peserta didik agar mempunyai kedisiplinan, keuletan dan kegigihan dalam beradaptasi dan berkompetensi pada dunia kerja sesuai dengan bidang keahlian, dan (4) membekali peserta didik dengan ilmu pengetahuan, teknologi, sosial, budaya dan seni agar mampu mengembangkan diri dikemudian hari baik secara mandiri maupun melalui jenjang pendidikan yang lebih tinggi.

lulusann SMK Negeri 1 Lintongnihuta ya diharapkan mampu bersaing didunia usaha khususnya bidang teknik bangunan sesuai dengan tujuan dari SMK. Untuk mewujudkan harapan tesebut, di SMK N 1 Lintongnihuta membekali siswa dengan mata pelajaran produktif untuk mendukung tercapainya lulusan bermutu, salah satunya adalah Ilmu Bahan Bangunan.

Pengetahuan Ilmu Bahan Bangunan merupakan program diklat yang mempelajari tentang bagaimana mendata, mendesain, melaksanakan dan memelihara bangunan terutama memilih bahan yang baik untuk bangunan.

Dari hasil observasi yang dilakukan penulis ke sekolah SMK Negeri 1 Lintongnihuta dengan guru mata pelajaran hasil belajar ilmu bahan bangunan siswa kelas $X$ Program keahlian Kontruksi Batu Beton Tahun Ajaran 2013/2014 pada semester ganjil

Tabel 1. Data Hasil Ulangan Harian Ilmu Bahan Bangunan Kelas X Program Keahlian Konstruksi Batu Beton TA. 2013/2014

\begin{tabular}{|c|c|c|c|c|}
\hline No & $\begin{array}{c}\text { Interval } \\
\text { kelas }\end{array}$ & Fo & Fv (\%) & Keterangan \\
\hline 1 & $9-10$ & 2 & $6,45 \%$ & $\begin{array}{c}\text { Sangat } \\
\text { Kompeten }\end{array}$ \\
\hline 2 & $8,0-8,9$ & 4 & $12,90 \%$ & Kompeten \\
\hline 3 & $7,0-7,9$ & 8 & $25,81 \%$ & $\begin{array}{l}\text { Cukup } \\
\text { Kompeten }\end{array}$ \\
\hline 4 & $<7,0$ & 17 & $54,84 \%$ & $\begin{array}{c}\text { Tidak } \\
\text { Kompeten }\end{array}$ \\
\hline & & 31 & $100 \%$ & \\
\hline
\end{tabular}

Dari tabel di atas, perolehan nilai tidak kompeten 54,84\% dan kompeten 45,16\%. Sehingga presentase hasil belajar siswa belum mencapai kriteria ketuntasan minimum (KKM) yang ditetapkan oleh sekolah yaitu $70 \%$. Data ini di dapat dari hasil wawancara pada hari senin tanggal 15 September dari pak Alpen selaku guru mata pelajaran ilmu bahan bangunan, Beliau mengatakan proses pembelajaran masih seperti biasa yaitu dengan menggunakan model ceramah, sehingga 
peneliti dapat menyimpulkan siswa tidak memperhatikan penjelasan guru.

Dengan diterapkannya model mind mapping diharapkan dapat mempermudah siswa dalam mempelajari Ilmu Bahan Bangunan sehingga kesulitan-kesulitan dan kejenuhan dalam proses belajar mengajar akan lebih baik. Pembelajaran dengan menerapkan model mind mapping akan membantu siswa untuk mengerti untuk memaksimalkan potensi pikiran siswa dengan menggunakan otak kanan dan otak kirinya secara simultan. Sehingga mengetahui kemampuan siswa dalam pemahaman dalam materi pembelajaran

Berdasarkan uraian di atas, peneliti tertarik dan mempunyai keinginan meneliti tentang pengaruh model mind mapping terhadap hasil belajar siswa.

\section{Kajian Pustaka}

\subsection{Hakekat Hasil Belajar Ilmu Bahan} Bangunan

2.1.1 Hasil Belajar

"hasil belajar dipengaruhi oleh pengetahuan (kognitif) meliputi: pemahaman, aplikasi, analisis, sistensis dan evaluasi; sikap (afektif) meliputi: memperhatikan, merespon, menghayati nilai, mengorganisasi dan memperhatikan nilai; serta keterampilan (psikomotorik) meliputi: Persepsi, Respon terbimbing, Respon mekanistis, dan Respon kompleks dari setiap ilmu serta aktifitas belajar yang dilakukan siswa".

Maka dapat disimpulkan oleh peneliti bahwa Hasil belajar dalam ilmu bahan banggunan adalah pelajaran teoritis mengenai bahan-bahan bangunan yang berkualitas terutama dalam karakteristik bahan-bahan konstruksi batu dan beton dari yang tidak tahu menjadi tahu.

\subsubsection{Materi Pembelajaran Ilmu Bangunan}

Sesuai dengan KD (Kompetensi Dasar) yang tertera dalam silabus SMK N 1 Lintongnihuta pada mata pelajaran Ilmu Bahan Bangunan materi yang diajarkan sebagai berikut :
a. Jenis-jenis
Kayu untuk Bahan Konstruksi
b. sifat dan karakteristik kayu sebagai bahan bangunan
c. Sifat-Sifat Mekanis Kayu (Sebagai Material Konstruksi)

2.2 Hakekat Model Pembelajran Mind Mapping

\subsubsection{Model Pembelajran}

Model adalah suatu cara atau prosedur yang dipergunakan untuk mencapai tujuan yang telah ditetapkan. Dalam kegiatan belajar mengajar, model diperlukan oleh guru dan penggunaannya bervariasi sesuai dengan tujuan yang ingin dicapai setelah pengajaran berakhir. Seorang guru tidak akan dapat melaksanakan tugasnya bila pendidik tidak menguasai satu pun model pembelajaran yang dikemukakan para ahli psikologi dan pendidikan (Djamarah, 2006).

Dari pendapat-pendapat tersebut dapat peneliti simpulkan bahwa Model Pembelajaran adalah suatu landasan yang disusun secara sistematik yang dapt digunakan atau dipilih oleh guru untuk menyajikan materi pelajaran yang mengatur efektivitas siswa dalam mencapai tujuan yang telah ditetapkan.

\subsubsection{Model Pembelajran Mind mapping \\ Model pembelajaran mind mapping} sangat baik digunakan untuk pengetahuan awal siswa atau untuk menemukan alternatif jawaban. Dipergunakan dalam kerja kelompok secara berpasangan (2 orang). Langkahlangkah pembelajarannya:

a. Menyampaikan kompetensi yang ingin dicapai.

b. Menyajikan materi dengan mind mapping.

c. Mengajukan pertanyaan yang berhubungan pelajaran dan membagikan lembar kerja.

d. Guru meminta siswa membentuk kelompok secara heterogen.

e. Menugaskan salah satu siswa dari kelompok itu menceritakan materi yang baru diterima dari guru dan pasangannya mendengar sambil membuat catatan-catatan kecil, kemudian berganti peran. Begitu juga kelompok lainnya.

f. Guru mengajarkan cara pembuatan mind mapping yaitu: Mulai dari kertas 


\section{Pengaruh Model Pembelajaran Peta Pikiran (Mind mapping) Terhadap Hasil Belajar Mata Pelajaran IImu Bahan Bangunan Pada Siswa Kelas X Program Keahlian Konstruksi Batu Beton SMK Negeri 1 Lintongnihuta}

putih polos berorientasi landscape, Gunakan pinsil, pulpen, atau spidol warna dengan jumlah sebanyak mungkin, dan tiap cabang berbeda warna, Buatlah garis lengkung yang bentuknya mengecil dari pangkal (central image) menuju ujung, Pada cabang utama yang dimulai dari central image menggunakan huruf kapital, sedangkan pada cabang menggunakan huruf kecil. Posisi antara garis dan huruf sama panjang, Kata yang mewaliki pesan yang ingin disampaikan jangan terlalu panjang sebab hal-hal yang penting saja harus ditulis, Buatlah kata-kata dengan gambar dengan tujuan mempermudah kita untuk mengingat.

g. Setiap kelompok secara bergilir menjelaskan mind mapping yang dibuat setiap kelompok.

h. Mengulangi/menjelaskan kembali materi yang kiranya belum dipahami siswa sekaligus memberikan tugas kepada siswa.

i. Siswa yang membuat Kesimpulan dan guru menyempurnakan kesimpulan yang dibuat oleh siswa.

Peta pikiran juga memiliki kelemahan antara lain menghabiskan waktu yang lebih lama dalam pembuatan konsep dasar, bagi siswa yang tidak bisa menggambarkan peta pikiran merupakan hal yang sukar, sering pembaca peta pikiran kurang mengerti membaca peta pikiran yang dibuat orang lain.

Berikut point-point terpenting dalam mengerjakan mind mapping dalam pembelajaran adalah :
a. Asosiasi
b. Gambar dan lambang (Simbol)
c. Warna
d. Kata Kunci

\subsection{Hakekat Pembelajaran Konvensional}

Pembelajaran konvensional dalam penelitian ini adalah pembelajaran yang biasa dilakukan guru dalam mengajar di SMK Negeri 1 Lintongnihuta, yaitu pembelajaran konvensional dengan menggunakan model ceramah. Langkah-lanhgkah pembelajaran konvensional sebagai berikut: a. Guru membuka pembelajaran dengan memberikan salam dan mengabsen siswa sekaligus member motivasi kepada siswa.

b. Guru menjelaskan materi pembelajaran hari ini.

c. Guru menyimpulkan materi pembelajarn yang diajarkan.

d. Guru memberikan tugas kepada siswa untuk dikerjakan di rumah serta Guru menutup pembelajaran dengan member salam kepada siswa.

2.4 Pengaruh Model Pembelajaran Peta Pikiran (Mind mapping) Terhadap Hasil Belajar Ilmu Bahan Bangunan Pada Siswa Kelas $X$ Program Keahlian Kontruksi Batu Beton SMK N 1 Lintongnihuta Tahun Ajaran 2014/2015.

Dalam proses pembelajaran ini sangat penting kerjasama yang baik antara guru dan anak didik. Model Pembelajaran mind map dapat mengubah informasi menjadi pengetahuan, wawasan dan tindakan. Informasi yang disajikan fokus pada bagianbagian penting, dan dapat mendorong siswa untuk mengeksplorasi dan mengelaborasinya lebih jauh mengenai hal yang siswa ketahui mengenai materi ilmu bahan bangunan dengan daya nalar siswa.

Dengan adanya model pembelajaran mind mapping diharapkan dapat meningkatkan hasil belajar ilmu bahan bangunan pada materi jenis-jenis , sifat dan karakteristik kayu sebagai bahan bangunan pada siswa kelas X Teknik Kontruksi Batu Beton SMK Negeri 1 Lintongnihuta Tahun Ajaran 2014/2015.

Selanjutnya penelitian ini merupakan penelitian eksperimental yang menyelidiki pengaruh model pembelajaran Mind mapping maka untuk keperluan ini diadakan perlakuan berupa penerapan model pembelajaran Mind mapping terhadap kelompok eksperimen dan tanpa perlakuan pada kelompok kontrol.

\subsection{Pengajuan Hipotesis}

Berdasarkan kerangka teoritis dan kerangka konseptual yang telah diuraikan sebelumnya, maka hipotesis penelitian ini dapat dirumuskan sebagai berikut:

a. Model pembelajaran Mind mapping memberikan hasil belajar yang berbeda dibandingkan dengan pembelajaran konvensional terhadap hasil belajar Ilmu 
Bahan Bangunan siswa kelas X Program Keahlian Kontruksi Batu Beton SMK Negeri 1 Lintongnihuta, Tahun Ajaran 2014/2015 .

b. Model pembelajaran Mind mapping memberikan hasil belajar yang lebih tinggi dibandingkan dengan pembelajaran konvensional terhadap hasil belajar Ilmu Bahan Bangunan siswa kelas X Program Keahlian Kontruksi Batu Beton SMK Negeri 1 Lintongnihuta, Tahun Ajaran 2014/2015.

\section{Metodologi Penelitian}

Penelitian ini di laksanakan di SMK Negeri 1 Lintongnihuta Program Keahlian Teknik Kontruksi Batu dan Beton pada mata pelajaran Ilmu Bahan Bangunan. Penelitian ini dilaksanakan pada kelas $X$ semester genap, tanggal 08 Desember sampai 15 januari Tahun

Pelajaran 2014/2015.

Subjek penelitian ini adalah siswa kelas $X$ SMK Negeri 1 Lintongnihuta Program Keahlian Kontruksi Batu dan Beton Tahun Pelajaran 2014/2015.

Metode penelitian yang dilaksanakan adalah penelitian quasi eksperimen yaitu penelitian yang berusaha mengetahui ada tidaknya pengaruh hasil belajar antara dua kelas yang diberikan perlakuan yang berbeda.

\subsection{Desain Penelitian}

Tabel 2. Desain Penelitian

Keterangan :

$\mathrm{A}_{1}$ : Kelompok Eksperimen

$\mathrm{A}_{2}$ : Kelompok Kontrol

$\mathrm{Y}_{1}$ : Kemampuan awal siswa sebelum

\begin{tabular}{|c|c|c|c|c|}
\hline \multicolumn{2}{|c|}{ Kelompok } & $\begin{array}{l}\text { Pree- } \\
\text { Tes }\end{array}$ & Perlakuan & $\begin{array}{l}\text { Post- } \\
\text { Tes }\end{array}$ \\
\hline \multicolumn{2}{|r|}{$\mathrm{A}_{1}$} & $\mathrm{Y}_{1}^{2}$ & $\mathrm{X}_{\mathrm{mm}}$ & $\mathrm{Y}_{2}{ }^{2}$ \\
\hline \multicolumn{2}{|r|}{$\mathrm{A}_{2}$} & $\mathrm{Y}_{1}$ & $X_{k}$ & $\mathrm{Y}_{2}{ }^{2}$ \\
\hline \multicolumn{5}{|c|}{$\begin{array}{l}\text { pembelajaran pada kelas eksperimen } \\
\text { dan pada kelas kontrol }\end{array}$} \\
\hline $\mathrm{X}_{\mathrm{mm}}$ & \multicolumn{4}{|c|}{$\begin{array}{l}\text { Perlakuan model pembelajaran Mind } \\
\text { mapping }\end{array}$} \\
\hline$X_{k}:$ & \multicolumn{4}{|c|}{ Perlakuan pembelajaran Konvensional. } \\
\hline $\mathrm{Y}_{2}$ : & $\begin{array}{l}\text { Hasil } \\
\text { pembel } \\
\text { mappin }\end{array}$ & $\begin{array}{l}\text { ajar } s \\
\text { can mes } \\
\text { an nem }\end{array}$ & $\begin{array}{l}\text { ra setelah } \\
\text { Junakan m } \\
\text { laiaran Konv }\end{array}$ & $\begin{array}{l}\text { berikan } \\
\text { el Mind } \\
\text { sional }\end{array}$ \\
\hline
\end{tabular}

\subsection{Teknik Pengumpulan Data}

Penelitian ini, teknik pengumpulan data dilakukan dengan menggunakan test objektif untuk data hasil belajar Ilmu Bangunan kepada masing-masing subjek penelitian. Test yang digunakan dalam bentuk pilihan berganda dengan empat option pilihan yaitu a, b, c, dan d. Kriteria penilaian adalah memberikan skor 1 untuk setiap soal yang dijawab benar dan skor 0 untuk setiap soal yang dijawab salah. Test ini mencakup semua materi yang diberikan selama perlakuan. Setelah dilaksanakan uji coba instrument pada kelas XI maka kisi-kisi soal dari 40 item soal menjadi 30 item soal yang valaid sehingga soal yang digunakan untuk penelitian sebanyak 30 butir soal.

\subsection{Uji Instrument Penelitian}

Sebelum test hasil belajar digunakan untuk mengumpulkan data terlebih dahulu uji tes dicoba untuk mengetahui apakah test telah memenuhi persyaratan validitas test, indeks kesukaran test, daya pembeda, dan reliabilitas test.

\subsubsection{Validitas Test}

Untuk mengetahui validitas test hasil belajar Ilmu Bangunan digunakan rumus Korelasi Point Biseral oleh Arikunto (2010) yaitu :

$$
r_{p b i s}=\frac{M_{p}-M_{t}}{S_{t}} \sqrt{\frac{P}{q}}
$$

Keterangan :

Rpbi $=$ Koefisien korelasi point biserial $\mathrm{Mp}=$ Mean skor dari subjek yang menjawab benar butir soal

$\mathrm{Mt}=$ Mean skor total (skor rata-rata dari seluruh peserta tes)

St $=$ Standar deviasi dari skor total

$\mathrm{p}$ = Proporsi siswa yang menjawab benar

$\mathrm{q}=$ Proporsi siswa yang menjawab salah ( $\mathrm{q}$ $=1-p)$

$$
\left(P=\frac{\text { banyaknya siswa yang menjawab benar }}{\text { Jumlah seluruh siswa }}\right)
$$

Rumus ini yang akan dipergunakan untuk menghitung $\mathrm{r}_{\text {hitung }}$ setiap butir soal, kemudian dibandingkan dengan $r_{\text {tabel }}$ pada taraf signifikan $5 \%$, dimana jika $r_{\text {tabel }}<$ $\mathrm{r}_{\text {hitung }}$ maka butir soal test tersebut dikatan valid, begitu juga sebaliknya, apabila $r_{\text {tabel }}$ $>r_{\text {hitung maka butir soal test tersebut }}$ dikatakan tidak valid dan tidak akan digunakan dalam uji instrument. Hasil 


\section{Pengaruh Model Pembelajaran Peta Pikiran (Mind mapping) Terhadap Hasil Belajar Mata Pelajaran IImu Bahan Bangunan Pada Siswa Kelas X Program Keahlian Konstruksi Batu Beton SMK Negeri 1 Lintongnihuta}

validitas tes pada soal no 1 adalah valid dimana r r ritung sebesar 0,375 dikonsultasikan dengan $r_{\text {tabel }}$ pada taraf signifikan $5 \%$ untuk $\mathrm{N}=30$ diperoleh $\mathrm{r}_{\text {tabel }}$ 0,361 . Sehingga diketahui bahwa item soal nomor 1 adalah valid. Hasil uji validitas dari 40 item soal yang valid adalah 30 item dan yang tidak valid 10 item soal yaitu: soal no 3, 8, 15, 20, 24, 30, 36, 37, 38, dan 39 . Maka soal yang dipergunakan pada tes hasil belajar adalah 30 soal.

\subsubsection{Indeks Kesukaran Test}

Menurut Arikunto (2010) soal baik adalah soal yang tidak terlalu mudah dan tidak terlalu sukar. Rumus mencari indeks kesukaran $(\mathrm{P})$ adalah:

Keterangan :

$$
P=\frac{B}{J}
$$

$\mathrm{P}=$ Indeks kesukaran

$\mathrm{B}$ = Banyak siswa yang menjawab benar

$\mathrm{J}=$ Jumlah seluruh peserta

Kriteria tingkat kesukaran soal yang dikemukakan oleh Arikunto (2010), adalah:

- Soal dengan P 0,00 sampai dengan 0,30 adalah soal sukar

- Soal dengan P 0,31 sampai dengan 0,70 adalah soal sedang

- Soal dengan P 0,71 sampai dengan 1,00 adalah soal mudah.

Arikunto (2010), Rumus yang digunakan untuk mengetahui daya pembeda setiap butir tes adalah :

$$
D=\frac{B_{A}}{J_{A}}-\frac{B_{B}}{J_{B}}
$$

Keterangan :

$\mathrm{D}$ = Daya pembeda butir soal

$\mathrm{B}_{\mathrm{A}}=$ Banyak peserta kelompok atas yang menjawab soal test benar

$\mathrm{B}_{\mathrm{B}}=$ Banyak peserta kelompok bawah yang menjawab soal test benar

$\mathrm{J}_{\mathrm{A}}=$ Banyak peserta kelompok atas

$\mathrm{J}_{\mathrm{B}}=$ Banyak peserta kelompok bawah

3.4.3 Reliabilitas Test

"Reliabilitas menunjukkan pada

suatu pengertian bahwa sesuatu instrumen cukup dapat dipercaya untuk digunakan sebagai alat pengumpul data karena instrumen tersebut sudah baik (Arikunto, 2010). rumus Kuder dan Richaderson (KR-20) yang diuraikan Arikunto (2010) sebagai berikut:

$$
r 11=\left(\frac{n}{n-1}\right)\left(\frac{\left.S^{2}-\sum p \cdot q\right)}{S^{2}}\right)
$$

Keterangan :

r11 = Reliabilitas tes secara keseluruhan

$\mathrm{n} \quad=$ Banyaknya item (butir tes)

$\mathrm{S}=$ Standart deviasi dari butir tes

$\mathrm{P}=$ Proporsi subjek yang menjawab butir soal dengan benar

$\mathrm{Q}=$ Proporsi subjek yang menjawab salah $(q=1-p)$

$\sum \mathrm{pq}=$ Jumlah hasil perkalian antara $\mathrm{p}$ dan $q$

Reliabilitas yang diperoleh dari hasil perhitungan dikonsultasikan dengan indeks korelasi yang diberikan Arikunto, yaitu sebagai berikut:

Antara 0,800 sampai dengan 1,000

$$
=\text { Sangat Tinggi }
$$

Antara 0,600 sampai dengan 0,799

$$
=\text { Tinggi }
$$

Antara 0,400 sampai dengan 0,599

$$
=\text { Sedang }
$$

Antara 0,200 sampai dengan 0,399

$$
=\text { Rendah }
$$

Antara 0,000 sampai dengan 0,199

$$
=\text { Sangat Rendah }
$$

Pada hitungan reabilitas soal di dapat harga $r_{\text {tabel }}$ diperoleh korelasi product moment person $\mathrm{a}=0,05$ dan $\mathrm{N}=30$ yaitu $0,361, r$ hitung $=0.9308$. sehingga harga $r_{\text {hitung }}>r_{\text {tabel, }}$ jadi dapat disimpulkan bahwa soal tersebut secara keseluruhan reliable.

\subsection{Teknik Analisis Data}

3.4.1 Deskripsi Data Penelitian

Dalam pendeskripsian data, adapun langkah-langkah yang ditempuh adalah sebagai berikut:

a. Menghitung rata-rata (Mean) dengan rumus (Sudjana, 2005) :

$$
\bar{x}=\frac{\sum x_{i}}{n}
$$

Keterangan : 
$\bar{X}=$ Mean

$\mathrm{X}=$ Jumlah Skor

$\mathrm{n}$ = Banyak data

Standart deviasi dihitung dengan rumus :

$$
S=\sqrt{\frac{N \sum X^{2}-\left(\sum X\right)^{2}}{N(N-1)}}
$$

Keterangan :

$\mathrm{N}=$ Jumlah subjek penelitian

$\sum X=$ Jumlah produk skor $X$

$\sum X^{2}=$ Jumlah Kuadrat produk skor $X$

\subsubsection{Uji Persyaratan Analisis}

Sebelum dilakukan uji hipotesis, maka data variabel penelitian harus memenuhi persayaratan normalitas dan homogenitas.

\section{Uji Normalitas}

Untuk menguji normalitas dengan menggunakan metode normalitas liliefors. Langkah-langkah yang dilakukan seperti yang dikemukakan oleh Sudjana (2005):

1) Mencari skor baru dengan menggunakan rumus :

$$
Z_{i}=\frac{X_{i}-\bar{X}}{S}
$$

Keterangan :

$$
\begin{aligned}
\mathrm{Z}_{\mathrm{i}} & =\text { Bilangan Baku } \\
\bar{X} & =\text { Rata-rata } \\
\mathrm{S} & =\text { Standar Deviasi }
\end{aligned}
$$

2) Untuk tiap bilangan baku dan menggunakan daftar distribusi normal baku, kemudian dihitung peluang $\mathrm{F}(\mathrm{Zi})$ $=\mathrm{P}(\mathrm{Z} \leq \mathrm{Zi})$

3) Selanjutnya menghitung proporsi $S(z i)$ dengan rumus :

$$
S=\frac{\text { banyaknya } Z_{1}, Z_{2,} \ldots \ldots \ldots Z_{n},<Z_{1}}{N}
$$

4) Menghitung selisih $\mathrm{F}(\mathrm{Zi})$ - $\mathrm{S}(\mathrm{Zi})$ kemudian menentukan harga mutlaknya.

5) Mengambil harga $L_{0}$ yaitu harga yang paling besar diantara harga mutlak, untuk menerima dan menolak hipotesis dibandingkan Lhitung dengan nilai kritis L yang diambil dari daftar nilai kritis uji liliefors dengan taraf signifikan $5 \%$.

6) Kriteria pengujiannya adalah : Jika Lhitung < Ltabel maka sampel berdistribusi normal.
Lhitung $>\mathrm{L}_{\text {tabel }}$ maka sampel tidak berdistribusi normal.

\section{Uji Homogenitas}

Homogenitas berfungsi untuk mengetahui apakah ada dua data penelitian memiliki kesamaan varian, syarat utama adalah apabila kedua data berdistribusi normal, homogenitas data penelitian dapat diuji dengan menggunakan uji Barlet dan membandingkan varian terbesar dan varian terkecil.

$$
F=\frac{\text { Varian terbesar }}{\text { Varian terkecil }}
$$

Kriteria pengujian adalah jika $\mathrm{F}$ hitung lebih kecil dari $\mathrm{F}$ tabel pada taraf signifikan 5\%, maka data hasil penelitian adalah homogen.

\section{Uji Hipotesis}

Sugiyono (2010) menyatakan bahwa "Hipotesis adalah suatu jawaban yang bersifat sementara terhadap masalah penelitian". Hipotesis adalah suatu jawaban yang bersifat sementara terhadap masalah penelitian

\begin{tabular}{|c|c|c|c|}
\hline $\begin{array}{c}\text { Sumber } \\
\text { Variasi } \\
\text { (SV) }\end{array}$ & $\begin{array}{c}\text { Jumlah } \\
\text { Kuadrat } \\
\text { (JK) }\end{array}$ & $\begin{array}{c}\text { Derajat } \\
\text { kebeba } \\
\text { san } \\
\text { (db) }\end{array}$ & $\begin{array}{c}\text { Mean } \\
\text { Kuadra } \\
\mathbf{t} \\
(\mathrm{MK})\end{array}$ \\
\hline $\begin{array}{l}\text { Kelompok } \\
\text { (K) }\end{array}$ & $\begin{array}{l}\mathrm{JK}_{\mathrm{k}}= \\
\sum \frac{\left(\sum X_{k}\right)^{2}}{n_{k}}-\frac{\left(\sum X_{T}\right)^{2}}{N}\end{array}$ & $\begin{array}{l}\mathrm{db}_{\mathrm{k}}=\mathrm{k} \\
-1\end{array}$ & $\begin{array}{l}\mathrm{MK}_{\mathrm{k}}= \\
\mathrm{JK}_{\mathrm{k}}: \mathrm{db}_{\mathrm{k}}\end{array}$ \\
\hline Dalam (d) & $\begin{array}{l}\mathrm{JK}_{\mathrm{d}}=\mathrm{JK}_{\mathrm{T}}-\mathrm{JK}_{\mathrm{k}} \\
\mathrm{JK} \mathrm{K}_{\mathrm{T}} \\
\sum X_{T}-\frac{\left(\sum X_{T}\right)^{2}}{N}\end{array}$ & $\begin{array}{l}\mathrm{db}_{\mathrm{d}}=\mathrm{N} \\
-\mathrm{K} \\
\mathrm{db}_{\mathrm{t}}=\mathrm{N} \\
-1\end{array}$ & $\begin{array}{l}\mathrm{Mk}_{\mathrm{d}}= \\
\mathrm{JK} \mathrm{d}_{\mathrm{d}}: \mathrm{db}_{\mathrm{d}}\end{array}$ \\
\hline
\end{tabular}
(Arikunto, 2010). Untuk pengujian hipotesis penelitian ini dilakukan dengan menggunakan Analisis Varians (ANAVA), selanjutnya jika berbeda dilanjutkan dengan rumus uji-t (Arikunto, 2000)

Tabel 3. Rumus Persiapan Analisis Varian

Keterangan :

$\mathrm{n}_{\mathrm{k}} \quad=$ jumlah subjek dalam kelompok

$\mathrm{k}=$ banyaknya kelompok

$\mathrm{N} \quad=$ jumlah subjek seluruhnya

$\frac{\left(\sum X_{T}\right)^{2}}{N}=$ faktor koreksi yang muncul

berkali-kali

Dengan $d b_{F}=d b_{k}$ lawan $d_{d}$ 


\section{Pengaruh Model Pembelajaran Peta Pikiran (Mind mapping) Terhadap Hasil Belajar Mata Pelajaran IImu Bahan Bangunan Pada Siswa Kelas X Program Keahlian Konstruksi Batu Beton SMK Negeri 1 Lintongnihuta}

Cara menentukan kesimpulan adalah sebagai berikut:

Tabel 4. Kesimpulan Perhitungan Anava

\begin{tabular}{|c|c|c|}
\hline Jika $F_{0} \geq F_{t}, 1 \%$ & $\begin{array}{c}\text { Jika } F_{0} \geq F_{t}, \\
5 \%\end{array}$ & $\begin{array}{c}\text { Jika } F_{5 \%} \leq F_{t}, \\
5 \%\end{array}$ \\
\hline $\begin{array}{l}\text { Harga } \mathrm{F}_{0} \text { yang } \\
\text { diperoleh sangat } \\
\text { signifikan }\end{array}$ & $\begin{array}{l}\text { Harga } F_{0} \text { yang } \\
\text { diperoleh } \\
\text { signifikan }\end{array}$ & $\begin{array}{l}\text { Harga } \mathrm{F}_{0} \\
\text { yang } \\
\text { diperoleh } \\
\text { tidak } \\
\text { signifikan }\end{array}$ \\
\hline $\begin{array}{l}\text { Ada perbedaan } \\
\text { mean secara } \\
\text { sangat signifikan }\end{array}$ & $\begin{array}{l}\text { Ada } \\
\text { perbedaan } \\
\text { mean secara } \\
\text { signifikan }\end{array}$ & $\begin{array}{l}\text { Tidak ada } \\
\text { perbedaan } \\
\text { mean yang } \\
\text { tidak } \\
\text { signifikan }\end{array}$ \\
\hline $\begin{array}{l}\text { Hipotesis nol }\left(\mathrm{H}_{0}\right) \\
\text { ditolak }\end{array}$ & $\begin{array}{l}\text { Hipotesis nol } \\
\left(\mathrm{H}_{0}\right) \text { ditolak }\end{array}$ & $\begin{array}{l}\text { Hipotesis nol } \\
\left(\mathrm{H}_{0}\right) \text { diterima }\end{array}$ \\
\hline $\mathrm{P}<0,01$ atau $=0,01$ & $\begin{array}{l}\mathrm{p}<0,05 \text { atau }= \\
0,05\end{array}$ & $p>0,05$ \\
\hline \multicolumn{3}{|c|}{$\begin{array}{l}\text { Apabila data penelitian berdistribusi } \\
\text { normal atau homogen, maka untuk menguji } \\
\text { hipotesisnya digunakan uji satu pihak yaitu } \\
\text { pihak kanan seperti (Arikunto, 2000): }\end{array}$} \\
\hline \multicolumn{2}{|c|}{$M_{1}-M_{2}$} & $(11)$ \\
\hline
\end{tabular}

dengan $\mathrm{db}$ (derajat kebebasan) $=\left(\mathrm{n}_{1}-\mathrm{n}_{2}-2\right)$

Keterangan :

$\mathrm{n}_{1} \quad=$ jumlah subjek pada kelas eksperimen (dengan pembelajaran Mind mapping)

$\mathrm{n}_{2}=$ jumlah subjek pada kelas kontrol

$\mathrm{M}_{1}=$ nilai rata-rata kelas dengan pembelajaran Mind mapping

$\mathrm{M}_{2} \quad$ = nilai rata-rata kelas tanpa pembelajaran Mind mapping

Mkd = Mean kuadrat dalam

Data yang dianalisis dibuat hipotesis sebagai berikut ini:

Ho : $\mathrm{PMM}=$ TPMM

$\mathrm{Ha} \quad$ : $\mathrm{PMM} \neq \mathrm{TPMM}$

Keterangan :

PMM :hasil belajar ilmu bahan bangunan yang dikenai pembelajaran Mind mapping
TPMM :hasil belajar ilmu bahan bangunan tanpa dikenai pembelajaran Mind mapping

Kriteria pengujiannya adalah terima $\mathrm{H}_{\mathrm{O}}$, jika $t<t_{1-\alpha}$ dimana $t_{1-\alpha}$ didapat dari daftar distribusi t dengan peluang (1-a) dan $d k=n_{1}+$ $n_{2}-2$ dan $\mathrm{a}=0,05$. Untuk harga $\mathrm{t}$ lainnya $\mathrm{H}_{\mathrm{O}}$ ditolak.

\section{Hasil Penelitian dan Pembahasan \\ 4.1 Data Pret-tes Hasil Belajar Siswa pada Kelas Eksperimen}

Pada tahapan penelitian, kedua sampel yaitu kelas eksperimen dan kontrol, peneliti melakukan pre-tes yang bertujuan untuk mengetahui seberapa besar kemampuan awal siswa pada kedua kelas terhadap hasil belajar Ilmu Bangunan sebelum diberikan perlakuan.

Berdasarkan data yang diperoleh dapat diketahui bahwa skor pre-tes (tes awal) pada kelas eksperimen diperoleh skor tertinggi $=23$ dan skor terendah $=7$, dengan rata-rata $=13,1$, standart deviasi $(\mathrm{SD})=3,71$ dan varians $=13,74$. Untuk melihat skor siswa digunakan kelas interval yaitu skor antara, frekuensi absolut yaitu jumlah siswa yang memiliki skor hasil belajar, dan frekuensi relatif yaitu jumlah persen skor hasil belajar seperti yang disajikan pada tabel di bawah ini.

Tabel 5. Distribusi Frekuensi Data Skor Pretes Siswa dengan Model pembelajaran Mind mappingKelas Eksperimen

\begin{tabular}{cccc}
\hline Kelas & $\begin{array}{c}\text { Interval } \\
\text { kelas }\end{array}$ & F.Absolut & $\begin{array}{c}\text { F. } \\
\text { Relatif }\end{array}$ \\
\hline 1 & $7-9$ & 6 & $20 \%$ \\
2 & $10-12$ & 9 & $30 \%$ \\
3 & $13-15$ & 7 & $23.34 \%$ \\
4 & $16-18$ & 6 & $20 \%$ \\
5 & $19-21$ & 1 & $3.33 \%$ \\
6 & $22-24$ & 1 & $3,33 \%$ \\
\hline & Jumlah & $\mathbf{3 0}$ & $\mathbf{1 0 0}$ \\
\hline
\end{tabular}

\subsection{Data Post-tes Hasil Belajar Siswa pada Kelas Eksperimen}

Berdasarkan data yang diperoleh dapat diketahui bahwa skor post-tes (tes akhir) pada kelas eksperimen diperoleh skor tertinggi $=28$ dan skor terendah $=18$, dengan rata-rata $=23,9$, standart deviasi $(\mathrm{SD})=2,47$ dan varians $=6,09$. Untuk melihat skor siswa digunakan kelas 
interval yaitu skor antara, frekuensi absolut yaitu jumlah siswa yang memiliki skor hasil belajar, dan frekuensi relatif yaitu jumlah persen skor hasil belajar seperti yang disajikan pada tabel di bawah ini .

Tabel 6. Distribusi Frekuensi Data Skor Posttes Siswa denga Model pembelajaran Mind mappingKelas Eksperimen

\begin{tabular}{|c|c|c|c|}
\hline Kelas & $\begin{array}{c}\text { Interval } \\
\text { kelas }\end{array}$ & F.Absolut & $\begin{array}{c}\text { F. } \\
\text { Relatif }\end{array}$ \\
\hline 1 & $17-18$ & 1 & $3,33 \%$ \\
\hline 2 & $19-20$ & 1 & $3,33 \%$ \\
\hline 3 & $21-22$ & 10 & $33,33 \%$ \\
\hline 4 & $23-24$ & 8 & $26,67 \%$ \\
\hline 5 & $25-26$ & 6 & $20 \%$ \\
\hline 6 & $27-28$ & 4 & $13,34 \%$ \\
\hline \multicolumn{2}{|r|}{ lah } & 30 & 100 \\
\hline
\end{tabular}

\subsection{Data Pret-tes Hasil Belajar Siswa pada Kelas Kontrol}

Berdasarkan data yang diperoleh dapat diketahui bahwa skor pre-tes (tes awal) pada kelas kontrol diperoleh skor tertinggi $=22$ dan skor terendah $=9$, dengan rata-rata $=13,27$, standart deviasi $(\mathrm{SD})=2,96$ dan varians $=8,76$ Untuk melihat skor siswa digunakan kelas interval yaitu skor antara, frekuensi absolut yaitu jumlah siswa yang memiliki skor hasil belajar, dan frekuensi relatif yaitu jumlah persen skor hasil belajar seperti yang disajikan pada tabel di bawah ini:

Tabel 7. Distribusi Frekuensi Data Skor Pretes Siswa yang Diajarkan dengan Model pembelajaran Konvensional

\begin{tabular}{cccc}
\hline kelas & $\begin{array}{c}\text { Interval } \\
\text { kelas }\end{array}$ & F.Absolut & $\begin{array}{c}\text { F. } \\
\text { Relatif }\end{array}$ \\
\hline 1 & $9-11$ & 8 & $26,67 \%$ \\
2 & $12-14$ & 8 & $26,67 \%$ \\
3 & $15-17$ & 11 & $36,67 \%$ \\
4 & $18-20$ & 2 & $6,66 \%$ \\
5 & $21-23$ & 1 & $3,33 \%$ \\
\hline & Jumlah & $\mathbf{3 0}$ & $\mathbf{1 0 0}$ \\
\hline
\end{tabular}

\subsection{Data Post -tes Hasil Belajar Siswa pada Kelas Kontrol}

Berdasarkan data yang diperoleh dapat diketahui bahwa skor post-tes pada kelas kontrol diperoleh skor tertinggi $=26$ dan skor terendah $=13$, dengan rata-rata $=19$, standart deviasi $(\mathrm{SD})=2,84$ dan varians $=8,07$. Untuk melihat skor siswa digunakan kelas interval yaitu skor antara, frekuensi absolut yaitu jumlah siswa yang memiliki skor hasil belajar, dan frekuensi relatif yaitu jumlah persen skor hasil belajar seperti yang disajikan pada tabel di bawah ini:

Tabel 8 . Distribusi Frekuensi Data Skor Posttes Siswa dengan Model pembelajaran Konvensional

\begin{tabular}{cccc}
\hline Kelas & $\begin{array}{c}\text { Interval } \\
\text { kelas }\end{array}$ & F.Absolut & $\begin{array}{c}\text { F. } \\
\text { Relatif }\end{array}$ \\
\hline 1 & $13-15$ & 2 & $6,67 \%$ \\
2 & $16-18$ & 8 & $26,67 \%$ \\
3 & $19-21$ & 14 & $46,67 \%$ \\
4 & $22-24$ & 5 & $16,66 \%$ \\
5 & $25-27$ & 1 & $3,33 \%$ \\
\hline \multicolumn{2}{r}{ Jumlah } & $\mathbf{3 0}$ & $\mathbf{1 0 0}$ \\
\hline
\end{tabular}

\subsection{Identifikasi Tingkat Kecendrungan} Variabel Penelitian

Untuk mengidentifikasi tingkat kecenderungan variabel penelitian dihitung dengan menggunakan nilai rata-rata ideal (Mi) $=15$ dan juga nilai standar deviasi ideal $(\mathrm{SDi})=$ 5,33, dengan rumus sebagai berikut:

$$
\begin{aligned}
M i & =\frac{\text { skor tertinggi ideal }+ \text { skor terendah ideal }}{2} \\
S D i & =\frac{\text { skor tertinggi ideal }- \text { skor terendah ideal }}{6}
\end{aligned}
$$

Berdasarkan data yang diperoleh pada kelas eksperimen dan kelas kontrol, maka dapat diperoleh tingkat kecenderungan hasil perhitungan tes hasil belajar pada kelas eksperimen dan kelas kontrol pada tabel-tabel berikut:

Tabel 9. Tingkat Kecendrungan Hasil Belajar Ilmu Bangunan pada Kelas Eksperimen

\begin{tabular}{cccc}
\hline Rentang & $\begin{array}{c}\text { F. } \\
\text { Absolut }\end{array}$ & $\begin{array}{c}\text { F. } \\
\text { Relatif }\end{array}$ & Kategori \\
\hline 22,5 s/d ke & 18 & $60 \%$ & Tinggi \\
atas & 12 & $40 \%$ & Cukup \\
15 s/d 22,5 & 12 & 0 & Kurang \\
7,5 s $/$ d 15 & 0 & 0 & Rendah \\
7,5 & 0 & $\mathbf{1 0 0} \%$ & \\
\hline Jumlah & $\mathbf{3 0}$ & \\
\hline
\end{tabular}

Berdasarkan perhitungan di atas diperoleh bahwa siswa kelas $X$ Program Keahlian Kontruksi Batu Beton di SMK Negeri 1 Lintongnihuta Tahun Pelajaran 2014/2015 pada 


\section{Pengaruh Model Pembelajaran Peta Pikiran (Mind mapping) Terhadap Hasil Belajar Mata Pelajaran IImu Bahan Bangunan Pada Siswa Kelas X Program Keahlian Konstruksi Batu Beton SMK Negeri 1 Lintongnihuta}

kelas eksperimen, mempunyai tingkat tes hasil belajar Ilmu Bangunan cenderung tinggi.

Tabel 10. Tingkat Kecendrungan Hasil Belajar Ilmu Bangunan pada Kelas Kontrol

\begin{tabular}{cccc}
\hline Rentang & $\begin{array}{c}\text { F. } \\
\text { Absolut }\end{array}$ & $\begin{array}{c}\text { F. } \\
\text { Relatif }\end{array}$ & Kategori \\
\hline $\begin{array}{c}22,5 \mathrm{~s} / \mathrm{d} \\
\text { ke atas }\end{array}$ & 3 & $10 \%$ & Tinggi \\
$15 \mathrm{~s} / \mathrm{d}$ & 25 & $83,33 \%$ & Cukup \\
22,5 & & $6,67 \%$ & $\begin{array}{c}\text { Kurang } \\
7,5 \mathrm{~s} / \mathrm{d} 15\end{array}$ \\
7,5 & 0 & 0 & Rendah \\
\hline Jumlah & $\mathbf{3 0}$ & $\mathbf{1 0 0} \%$ & \\
\hline
\end{tabular}

Berdasarkan perhitungan di atas diperoleh bahwa siswa kelas $X$ Program Keahlian Kontruksi Batu Beton di SMK Negeri 1 Lintongnihuta Tahun Ajaran 2014/2015 pada kelas kontrol, mempunyai tingkat tes hasil belajar Ilmu Bangunan cenderung cukup.

\subsection{Uji Persyaratan Analisis}

\subsubsection{Uji Normalitas}

Salah satu persyaratan analisis yang harus dipenuhi agar dapat menggunakan statistik parametik adalah sebaran data setiap penelitian harus berdistribusi normal. Pengujian normal tidaknya data dilakukan dengan menggunakan rumus uji lilliefors. Syarat normal dipenuhi apabila $\mathrm{L}_{\text {hitung }}<\mathrm{L}_{\text {tabel }}$ pada taraf $\alpha=5 \%$.

Tabel 11. Rumus uji lilliefors. Syarat normal dipenuhi apabila Lhitung $<\mathrm{L}_{\text {tabel }}$ pada taraf $\alpha=5 \%$.

\begin{tabular}{lccc}
\hline $\begin{array}{c}\text { Kelompok } \\
\text { Interval }\end{array}$ & $\begin{array}{c}\text { F. } \\
\text { Absolut }\end{array}$ & $\begin{array}{c}\text { F. } \\
\text { Relatif }\end{array}$ & $\begin{array}{c}\text { Katego } \\
\text { ri }\end{array}$ \\
\hline $\mathrm{Mi}+1,5 \mathrm{Sdi}$ & $\mathrm{n}_{1}$ & $\mathrm{n}_{1} / \mathrm{n} \times$ & Tinggi \\
s/d ke atas & & $100 \%$ & \\
Mi s/d Mi + & $\mathrm{n}_{2}$ & $\mathrm{n}_{2} / \mathrm{n} \times$ & Cukup \\
1,5 Sdi & & $100 \%$ & \\
$\mathrm{Mi}-1,5 \mathrm{SDi}$ & $\mathrm{n}_{3}$ & $\mathrm{n}_{3} / \mathrm{n} \times$ & Kurang \\
s/d Mi & & $100 \%$ & \\
Mi - 1,5 SDi & $\mathrm{n}_{4}$ & $\mathrm{n}_{4} / \mathrm{n} \times$ & Rendah \\
s/d ke bawah & & $100 \%$ & \\
\hline
\end{tabular}

Tabel 12. Ringkasan Uji Normalitas Data dengan Litosfer

\begin{tabular}{|c|c|c|c|c|c|}
\hline $\begin{array}{l}\mathbf{N} \\
\mathbf{o}\end{array}$ & $\begin{array}{c}\text { Da } \\
\text { ta }\end{array}$ & Kelas & $\begin{array}{c}\text { L } \\
\text { hitung }\end{array}$ & $\begin{array}{c}\mathbf{L} \\
\text { tabel }\end{array}$ & $\begin{array}{l}\text { Kesim } \\
\text { pulan }\end{array}$ \\
\hline 1 & Pre- & $\begin{array}{l}\text { Eksperi } \\
\text { men }\end{array}$ & 0,0210 & 0,161 & Normal \\
\hline 2 & tes & Kontrol & 0,1523 & 0,161 & Normal \\
\hline 3 & Pos- & $\begin{array}{l}\text { Eksperi } \\
\text { men }\end{array}$ & 0,1236 & 0,161 & Normal \\
\hline 4 & & Kontrol & 0,1333 & 0,161 & Normal \\
\hline
\end{tabular}

Dengan demikian nilai pre-tes kelas eksperimen dan kontrol $\mathrm{L}_{\text {hitung }}<\mathrm{L}_{\text {tabel, }}$ sedangkan nilai pos-tes kelas eksperimen dan kontrol Lhitung < Ltabel, maka dapat disimpulkan bahwa data kedua kelompok sampel berdistribusi normal.

\subsubsection{Uji Homogenitas}

Data yang telah diuji normalitasnya, perlu diuji homogenitasnya. Uji homogenitas dilakukan untuk mengetahui variasi populasi yaitu untuk mengetahui apakah data-data penelitian homogen atau tidak homogen dengan menggunakan rumus uji F. Analisis uji homogenitas yang menggunakan uji $\mathrm{F}$ yaitu membandingkan varians terbesar dan varians terkecil yaitu:

$$
F=\frac{\text { Varian terbesar }}{\text { Varian terkecil }}=\frac{S_{1}^{2}}{S_{2}^{2}}
$$

Tabel 13. Ringkasan Uji Homogenitas Data

\begin{tabular}{rrrrrc}
\hline $\begin{array}{l}\mathbf{N} \\
\mathbf{0}\end{array}$ & $\begin{array}{c}\text { Da } \\
\text { ta }\end{array}$ & Kelas & $\begin{array}{c}\mathbf{F} \\
\text { hitung }\end{array}$ & $\begin{array}{c}\mathbf{F} \\
\text { tabel }\end{array}$ & $\begin{array}{c}\text { Kesim } \\
\text { pulan }\end{array}$ \\
\hline 1 & $\begin{array}{c}\text { Pre } \\
\text { 2 }\end{array}$ & $\begin{array}{l}\text { Eksperi } \\
\text { men }\end{array}$ & 1,57 & 1,65 & $\begin{array}{c}\text { Homo } \\
\text { gen }\end{array}$ \\
& & $\begin{array}{l}\text { Kontrol } \\
2\end{array}$ & & &
\end{tabular}

3 Eksperi

3 Pos men 1,33 1,65 Homo

4 -tes Kontrol 1,33 1,65 gen

Sehingga dapat dilihat bahwa $\mathrm{F}_{\text {hitung }}$ $<\mathrm{F}_{\text {tabel }}$ pada taraf nyata $a=5 \%$ yang berarti data kedua sampel memiliki varians yang homogen dan berdasarkan tabel dapat disimpulkan bahwa data penelitian telah memenuhi syarat untuk dilakukan pengujian hipotesis.

\subsubsection{Uji Hipotesis}

Setelah diketahui data di atas berdistribusi normal serta homogen terhadap kedua kelompok perlakuan, 
maka selanjutnya dilakukan uji hipotesis untuk mengetahui apakah terdapat pengaruh yang berbeda antara hasil belajar siswa yang diajar dengan menggunakan model Mind mapping dan hasil belajar siswa yang diajar dengan pembelajaran Konvensional dengan menggunakan rumus Analisis Varians (ANAVA) satu jalan.

Tabel 14. Pengujian Hipotesis Analisis Varians

\begin{tabular}{cccc}
\hline $\begin{array}{c}\text { Sumber } \\
\text { Data }\end{array}$ & $\mathbf{F}_{\mathbf{0}}$ & $\mathbf{F}_{\mathbf{t}} \mathbf{5} \%$ & Kesimpulan \\
\hline Pre-tes & 0,03 & 4,008 & $\begin{array}{c}\mathrm{H}_{0}: \mu_{1}=\mu_{2} \\
\text { diterima }\end{array}$ \\
Post-tes & 50,948 & 4,008 & $\begin{array}{c}\mathrm{H}_{0}: \mu_{1}=\mu_{2} \\
\text { ditolak }\end{array}$ \\
\hline
\end{tabular}

Dari hasil perhitungan uji hipotesis dengan rumus Analisis Varians satu jalan pada data pre-tes diperoleh bahwa $\mathrm{F}_{\text {hitung }}=$ 0,03 lebih kecil dari $\mathrm{F}_{\text {tabel }}=4,008$, maka hipotesis $\mathrm{H}_{0}: \mu_{1}=\mu_{2}$ diterima dalam taraf nyata 0,05 , sehingga dapat disimpulkan bahwa Model pembelajaran Mind mapping memberikan hasil belajar yang berbeda dibandingkan dengan pembelajaran konvensional terhadap hasil belajar Ilmu Bahan Bangunan siswa kelas X Program Keahlian Kontruksi Batu Beton SMK Negeri 1 Lintongnihuta, Tahun Ajaran 2014/2015.

Sedangkan dari hasil perhitungan uji hipotesis dengan rumus Anava Varians satu jalan pada data post-tes diperoleh bahwa $F_{\text {hitung }}=50,948$ lebih besar dari $F_{\text {tabel }}$ $=4,008$, maka $\mathrm{H}_{0}: \mu_{1}=\mu_{2}$ ditolak dan $\mathrm{H}_{1}$ : $\mu_{1} \neq \mu_{2}$ diterima, dengan demikian hasil belajar Ilmu Bangunan antara kelas eksperimen dan kelas kontrol jelas menunjukkan perbedaan, sehingga dapat dilanjutkan dengan uji-t. Dari perhitungan uji-t diperoleh $t_{\text {hitung }}=7,138$ dan $t_{\text {tabel }}=$ 1,689, karena $t_{\text {hitung }}>t_{\text {tabel, }}$ maka $\mathrm{H}_{\mathrm{a}}$ diterima dan $\mathrm{H}_{0}$ ditolak, dan oleh karena itu dapat disimpulkan bahwa penggunaan Model pembelajaran Mind mapping memberikan hasil belajar yang lebih baik dibandingkan dengan pembelajaran konvensional terhadap hasil belajar Ilmu Bahan Bangunan siswa kelas X Program Keahlian Kontruksi Batu Beton SMK
Negeri 1 Lintongnihuta, Tahun Ajaran 2014/2015.

\subsection{Pembahasan Penelitian}

Penelitian ini tergolong dalam penelitian quasi eksperimen yang melibatkan dua kelas yaitu kelas X KBB-1 dan kelas X KBB-2 yang diberi pelakuan yang berbeda, yaitu kelas eksperimen dengan model pembelajaran Mind mapping dan kelas kontrol dengan pembelajaran Konvensional. Pada awal penelitian ini diberikan tes awal kepada kelas eksperimen dan kelas kontrol, dan dari hasil tes awal yang dilakukan diperoleh skor rata-rata yaitu, untuk kelas eksperimen sebesar 13,1 dengan skor tertinggi 23 dan skor terendah 7 , sedangkan kelas kontrol sebesar 13,27 dengan skor tertinggi 22 dan skor terendah 9. Dari hasil uji hipotesis dengan rumus Analisis Varians (ANAVA) satu jalan, diperoleh bahwa $F_{\text {hitung }}=$ 0,03 lebih kecil dari $\mathrm{F}_{\text {tabel }}=4,008$, maka $\mathrm{H}_{0}: \mu_{1}=$ $\mu_{2}$ diterima dalam taraf nyata 0,05 , sehingga dapat disimpulkan bahwa tidak ada perbedaan secara nyata untuk kedua model pembelajaran tersebut sebelum diberi perlakuan kepada kelas eksperimen dan kelas kontrol, dengan kata lain kemampuan awal siswa pada kelas eksperimen sama dengan kemampuan awal siswa pada kelas kontrol.

Setelah diketahui bahwa hasil belajar kedua kelas tersebut tidak berbeda secara nyata, kemudian dilakukan pembelajaran Mind mapping pada kelas eksperimen dan pembelajaran Konvensional pada kelas kontrol. Dalam pemberian tes akhir hasil belajar pada kedua kelas diperoleh skor rata-rata yaitu untuk kelas eksperimen sebesar 23,9 dengan skor tertinggi 28 dan skor terendah 18, sedangkan skor rata-rata untuk kelas kontrol sebesar 19 dengan skor tertinggi 26 dan skor terendah 13. Dari hasil uji hipotesis dengan rumus Analisis Varians (ANAVA) satu jalan, diperoleh bahwa $\mathrm{F}_{\text {hitung }}=50,948$ lebih besar dari $\mathrm{F}_{\text {tabel }}=4,008$, maka $\mathrm{H}_{0}: \mu_{1}=\mu_{2}$ ditolak dan $\mathrm{H}_{1}$ : $\mu_{1} \neq \mu_{2}$ diterima, dengan demikian hasil belajar Ilmu Bangunan antara kelas eksperimen dan kelas kontrol jelas menunjukkan perbedaan, sehingga dapat dilanjutkan dengan uji-t. Dari perhitungan uji-t diperoleh $t_{\text {hitung }}=7,138$ dan $t_{\text {tabel }}=1,689$, karena $t_{\text {hitung }}>t_{\text {tabel, }}$ maka $\mathrm{H}_{\mathrm{a}}$ diterima dan $\mathrm{H}_{0}$ ditolak, dan oleh karena itu dapat disimpulkan bahwa model Mind mapping memberi pengaruh yang berbeda dibandingkan 


\section{Pengaruh Model Pembelajaran Peta Pikiran (Mind mapping) Terhadap Hasil Belajar Mata Pelajaran IImu Bahan Bangunan Pada Siswa Kelas X Program Keahlian Konstruksi Batu Beton SMK Negeri 1 Lintongnihuta}

dengan pembelajaran konvensional terhadap hasil belajar Ilmu Bahan Bangunan pada siswa kelas X Program Keahlian Kontruksi Batu Beton di SMK Negeri 1 Lintongnihuta Tahun Pelajaran 2014/2015. Dari hasil penelitian ini juga diperoleh temuan bahwa rata-rata peningkatan hasil belajar siswa yang diajarkan dengan model Mind mapping lebih tinggi.

Dengan demikian dari hasil penelitian bahwa pengujian hipotesis pertama dapat diterima yaitu: Model pembelajaran Mind mapping memberikan hasil belajar yang berbeda dibandingkan dengan pembelajaran konvensional terhadap hasil belajar Ilmu Bahan Bangunan siswa kelas X Program Keahlian Kontruksi Batu Beton SMK Negeri 1 Lintongnihuta, Tahun Ajaran 2014/2015. Dan pengujian hipotesis yang kedua dapat diterima yaitu: Model pembelajaran Mind mapping memberikan pengaruh yang lebih tinggi yaitu 7,138 dibandingkan dengan pembelajaran konvensional sebesar 1,689 terhadap hasil belajar Ilmu Bahan Bangunan siswa kelas $X$ Program Keahlian Kontruksi Batu Beton SMK Negeri 1 Lintongnihuta, Tahun Ajaran 2014/2015.

\section{Kesimpulan, Implikasi dan Saran}

\subsection{Kesimpulan}

Berdasarkan hasil penelitian dan pembahasannya, maka dapat diambil kesimpulan sebagai berikut:

a. Bedasarkan pengujian hipotesis bahwa Model pembelajaran Mind mapping memberikan pengaruh yang berbeda dibandingkan dengan pembelajaran konvensional terhadap hasil belajar Ilmu Bahan Bangunan setelah diberi perlakuan dilihat dari perhitungan anava satu jalan yaitu $\mathrm{F}_{\text {hitung }}=50,948$ lebih besar dari $\mathrm{F}_{\text {tabel }}=$ 4,008 .

b. Dari hasil perhitungan hipotesis yang kedua membuktikan bahwa pengaruh yang diajar menggunakan model mind mapping lebih tinggi dibandingkan hasil belajar siswa yang diajar menggunakan pembelajaran konvesional dilihat dari tabel perhitungan diperoleh $t_{\text {hitung }}=7,138$ dan $t_{\text {tabel }}=1,689$, karena $t_{\text {hitung }} 7,138>t_{\text {tabel }}=1,689$.

\subsection{Implikasi}

Berdasarkan hasil penelitian dan kesimpulan, peneliti mengimplikasikan bahwa tahapan-tahapan pembelajaran mind mapping dari pengajuan hipotesis pertama dapat diterima, yaitu Model pembelajaran Mind mapping memberikan hasil belajar yang berbeda dibandingkan dengan pembelajaran konvensional terhadap hasil belajar Ilmu Bahan Bangunan siswa kelas X. Adanya perbedahan hasil belajar dikarenakan model pembelajaran mind mapping untuk memudahkan menggali informasi diluar otak dan mudah melihat gambar keseluruhan sehingga pembelajaran tidak membosankan untuk mengingat pembelajaran lebih cepat dengan pembelajaran berkelompok.

Dari pengajuan hipotesis kedua dapat diterima, yaitu Model pembelajaran Mind mapping memberikan hasil belajar yang lebih baik dibandingkan dengan pembelajaran konvensional terhadap hasil belajar Ilmu Bahan Bangunan siswa kelas X. Adanya hasil yang lebih baik dilihat dari siswa lebih cepat menerima pembelajaran mind mapping dengan hasil belajar pembelajaran lebih tinggi dengan model pembelajaran mind mapping dibndingkan pembelajaran konvensional. Hal ini dikarenakan model pembelajaran mind mapping berpusat kepada siswa akan tetapi tidak mengesampingkan tugas dari guru. Dimana guru hanya sebagai fasilitator dalam proses pembelajaran. Model pembelajaran mind mapping ini sangat membentuk siswa untuk menjadi kreatif, menyenangkan, berkonsentrasi belajar lebih cepat, mudah dan efesien dengan unsur terpenting dari model mind mapping yaitu asosiasi, lambang dan gambar (simbol), warna, kata kunci.

\subsection{Saran}

Berdasarkan hasil penelitian yang diperoleh, maka peneliti memberikan saran sebagai berikut:

a. Model pembelajaran mind mapping dapat digunakan sebagai salah satu model pembelajaran di dalam meningkatkan hasil belajar Ilmu Bahan Bangunan.

b. Bagi guru dan calon guru hendaknya menerapkan Model pembelajaran mind mapping ini dalam proses belajar mengajar.

c. Bagi guru dan calon guru disarankan agar memiliki persiapan yang baik dan terlebih dahulu memperkenalkan model 
pengajaran ini kepada siswa, sehingga pembelajaran dapat berjalan dengan waktu yang lebih efektif.

d. Untuk penelitian lanjutan dengan variabel yang relevan hendaknya dapat memperbaiki kekurangan yang ada pada penelitian ini dengan membuat perencanaan penelitian yang lebih baik lagi untuk mendapatkan hasil yang diinginkan.

\section{Daftar Pustaka}

Abdurrahman. 2003. Evaluasi Hasil Belajar. Jakarta: Rineka Cipta.

Arikunto, Suharsimi. 2006. Dasar-Dasar Evaluasi Pendidikan. Jakarta : Bumi Aksara

Arikunto, Suharsimi. 2000. Manajemen Penelitian (Edisi baru). Jakarta: Rineka Cipta.

Buzan, Tony. 2004. Buku Pintar Mind mapping. Jakarta: PT. Gramedia Pustaka Utama.

Djamarah, Syaiful Bahri dan Aswan Zain. 2006. Strategi Belajar Mengajar (Edisi Revisi). Jakarta: Rineka Cipta.

Frick, Heinz. 1980. Ilmu Konstruksi Bangunan 1. Yogyakarta: Kanisius.

Gunawan, Adi. 2008. Genius Learning Strategi. Jakarta : Kompas Gramedia.

Hamalik, Oemar. 2008. Kurikulum dan Pembelajaran. Jakarta: PT. Bumi Aksara.

Manik, Ida Motmauli. 2010. Pengaruh Pembelajaran Kooperatif Teknik Jigsaw Terhadap Hasil Belajar PDTB Pada Siswa Kelas X Program Keahlian Teknik Gambar Bangunan Di SMK Negeri 1 Lintongnihuta Tahun Ajaran 2010/2011. Skripsi. Medan: Universitas Negeri Medan.

Mulyono, Tri. 2003. Teknologi Beton. Yogyakarta: CV. Andi Offset.

Nelson, 2010. Soal-soal Ilmu Bahan Bangunan. http://blogspot.com_holil/. Diakses 10 Oktober 2014.

Olivia, Femi. 2009. Asik Mind mapping Pelajaran Sekolah. Jakarta: PT.Elex Media Komputindo.

Sagala, Syaiful. 2009. Konsep dan Makna Pembelajaran. Bandung: Alfabeta.
Sardiman. 2009. Interaksi dan Motivasi Belajar Mengajar. Jakarta: PT. Raja Grasindo Persada.

Slameto. 2003. Belajar dan Faktor-faktor yang Mempengaruhinya. Jakarta: Rineka Cipta.

Sabri, A. 2007. Strategi Belajar Mengajar. Jakarta : Reneka Cipta.

Sanjaya, Wina. 2008. Strategi Pembelajaran. Jakarta : Kencana.

Sudjana, Nana. 2005. Metoda Statistika. Bandung: Tarsito.

Sudjana, Nana. 2009. Penilaian Hasil Proses Belajar Mengajar. Jakarta: PT. Remaja Rosdakarya.

Sugiyono. 2010. Metode Penelitian Pendidikan. Bandung: Alfabeta

Trianto. 2009. Mendesain Model Pembelajaran Inovatif Progresif. Jakarta : Kencana

UUR. 1. No. 20 Tahun 2003, Bab I. Pasal I.

Windura, Sutanto. 2013. Mind Map. Jakarta : Kompas Gramedia.

Wilis. 2003. Perencanaan Pembelajaran. Jakarta : Reneka Cipta 